\title{
Effect of Antidiuretic Hormone Upon Urinary Concentrating Ability and Medullary c-AMP Formation in Neonatal Piglets
}

\author{
R. JOPPICH, U. KIEMANN, G. MAYER, and D. HÄBERLE
}

\begin{abstract}
Universitäts-Kinderklinik of the University of Munich, Lindwurmstrasse 4,8 Munich 2, Federal Republic of Germany and Physiologisches Institut of the University of Munich, (D. H.). Pettenkoferstrasse 12,8 Munich 2, Federal Republic of Germany
\end{abstract}

\section{Summary}

In 16 anesthetized piglets, the effects of 1-deamino-8-D-arginine-vasopressin (DDAVP) upon urinary flow rate, relative urinary osmolarity $\left(U / P_{\text {osmol }}\right)$, fractional water excretion $\left(U / P_{\ln }\right)$, fractional urca excretion $\left(U / P_{\text {urea }} / U / P_{I n}\right)$, renal adenosine $3 ', 5^{\prime}$-cyclic monophosphate (c-AMP) formation rate, and medullary c-AMP content were studied during the first 6 days of life. Glomerular filtration rate (GFR) was $0.19 \pm 0.09 \mathrm{ml} / \mathrm{min} / \mathrm{g}$ kidney wt (means $\pm \mathrm{SD}$ ) on day 1 and increased to $0.51 \pm 0.11 \mathrm{ml} / \mathrm{min} / \mathrm{g}$ kidney wt on day 6 . It was not affected by the application of $20 \mu \mathrm{g}$ DDAVP/ $\mathrm{kg}$ body wt. On day $1, \mathrm{U} / \mathrm{P}_{\text {osmol }}(1.81 \pm 0.29)$, urinary flow rate $(5.36 \pm 1.49 \mu \mathrm{l} / \mathrm{min} / \mathrm{g}$ kidney $\mathrm{wt}), \mathrm{U} / \mathrm{P}_{\ln }(31.67 \pm 6.10)$ and $\mathrm{U} /$ $P_{u r e a} / U / P_{\text {In }}(0.84 \pm 0.12)$ were not affected by DDAVP application. From day 2 onward, the reponse of these variables to application of DDAVP increased progressively. On day 6 , the following responses were observed: Urinary flow rate decreased from 13.85 $\pm 7.02 \mu \mathrm{l} / \mathrm{min} / \mathrm{g}$ kidney wt before DDAVP to $5.07 \pm 2.19 \mu \mathrm{l} / \mathrm{min} /$ g kidney wt after DDAVP. U/P $P_{\text {osmol }}$ raised from $1.24 \pm 0.27$ before DDAVP to $2.64 \pm 0.17$ after DDAVP. $U / P_{I n}$ increased from $36.85 \pm 13.11$ before DDAVP to $109.39 \pm 22.00$ after DDAVP. $U / P_{\text {urea }} / U / P_{\text {In }}$ decreased from $0.75 \pm 0.05$ before DDAVP to $0.55 \pm 0.04$ after DDAVP. These data indicate that the small solute permeability of the medullary collecting ducts becomes increasingly sensitive to antidiuretic hormone (ADI) during this period.

The increase in responsiveness of the urinary concentrating system with age was paralleled by the effect of DDAVP on renal c-AMP formation rate. In the diuretic control state, no correlation between renal c-AMP formation rate and the number of days was observed. However, after the application of DDAVP, the nephrogenic fraction of renal c-AMP excretion rate increased from 10.58 $\pm 4.49 \mathrm{pmole} / \mathrm{min} / \mathrm{g}$ kidney $w \mathrm{t}$ on day 1 to $21.61 \pm 8.10 \mathrm{pmole} /$ $\mathrm{min} / \mathrm{g}$ kidney wt on day 6 . Similar results were observed with the medullary c-AMP content. In diuretic control animals which had not received DDAVP, the medullary c-AMP content ranged between $636 \pm 257$ pmole $/ g$ wet wt on day 1 and $622 \pm 75$ pmole $/ g$ wet wt on day 6 . However, in animals which had been infused with DDAVP, medullary c-AMP content increased from $684 \pm 274$ pmole/g wet wt on day 1 to $1536 \pm 316$ pmole/g wet wt on day 6 .

\section{Speculation}

The unresponsiveness of the medullary adenylatecyclase to ADI in the newborn kidney might restrict, in addition to other parameters, the renal concentrating ability during the neonatal period.

It is generally acknowledged that the concentrating ability of the newborn kidney is reduced in comparison to that of the mature kidney. In the past, this phenomenon was predominately attrib- uted to the structural immaturity of the renal medulla $(2,22)$, to the reduced GFR and to the anabolic state of the neonatal metabolism, which together result in low filtration-, reabsorption-, and excretion rate of urea $(5,6)$. It was argued that in spite of the effects of ADH on the permeability of the collecting ducts, no significant amounts of water and urea could be reabsorbed, thus restricting the increase in urinary osmolarity.

More recent studies (18) focused upon the fact that the neonatal concentrating system is highly insensitive to $\mathrm{ADH}$. This concept was strongly supported by findings on membrane preparations of newborn rats in vitro which demonstrated that the activity of the ADH dependent adenylate-cyclase is reduced in comparison to the adult state $(19,21)$. Hence, it is possible that, in addition to the immaturity of the countercurrent system and the parameters mentioned above, a lack of intracellular c-AMP formation as a consequence of the reduced enzyme activity could be responsible, at least in part, for the diminished concentrating capacity of the newborn kidney.

In order to examine this theory, we performed clearance studies and measurements of the medullary c-AMP content on piglets in the neonatal period to determine whether there exists a parallelism between the development of renal concentrating capacity and the responsiveness of the $\mathrm{ADH}$ dependent c-AMP system to supramaximal doses of DDAVP.

\section{METHODS}

\section{GENERAL PROCEDURES}

Piglets (strain: Deutsche Landrasse) weighing between 600 and $2600 \mathrm{~g}$ and ranging in age between day 1 and 6 after birth were anesthetized by ip injection of $60-100 \mathrm{mg} / \mathrm{kg}$ of body wt of Inactin (Byk-Gulden, Konstranz, West Germany). During the experiments, Nembutal (Boehringer Sohn, Ingelheim am Rhein, West Germany) was injected iv at doeses between 5 and $10 \mathrm{mg} / \mathrm{kg}$ body wt as required. Body temperature was maintained at $37^{\circ} \mathrm{C}$ by a heated operating table. The trachea was cannulated and the right external jugular vein was catheterized for infusion of inulin and isotonic glucose solutions. The right femoral artery was catheterized in order to sample blood and measure arterial blood pressure. The urinary bladder was exposed by a median suprapubical incision and each ureter cannulated for sampling of urine specimens.

\section{EXPERIMENTAL PROCEDURE}

Control Measurements. After completion of surgery, the piglets received an infusion of isotonic glucose solution at a rate of 30 $\mathrm{ml} / \mathrm{hr} / \mathrm{kg}$ body wt and an infusion of inulin at a rate of 18.75 $\mathrm{mg} / \mathrm{min} / \mathrm{kg}$ body wt over a period of about $3 \mathrm{hr}$. This procedure induced a diuresis. After this period, both urinary flow rate and inulin concentration in plasma reached steady state. Inulin-, 
urea-, and c-AMP-clearance as well as $\mathrm{U} / \mathrm{P}_{\text {osmol }}$ were then determined for control. Three $\mathrm{ml}$ of arterial blood were sampled at the midpoint of each clearance period.

Clearance measurements during and after the infusion of DDAVP. After the control measurements were finished, glucose infusion was stopped in order to avoid fluid imbalance, but the inulin infusion was continued at the same rate. Thirty min later, when urinary flow rate had decreased markedly, $20 \mu \mathrm{g} / \mathrm{kg}$ body wt DDAVP (Ferring Sveden) was infused iv over a period of $20 \mathrm{~min}$. Even at such supramaximal doses, the drug has no significant vasoconstrictor effects (26). Clearance measurements as described above, were then performed for at least $3 \mathrm{hr}$. The response to DDAVP was assumed to be complete when urinary osmolarity didn't increase further during three consecutive clearance periods. When measurements were finished, both kidneys were immediately removed and frozen in liquid nitrogen.

Measurement of medullary $c-A M P$ content. In order to measure medullary c-AMP content, experiments on two groups of 16 animals were performed according to the protocol described above. The age of the animals ranged between day 1 and day 6 after birth. One group which served for control, received only glucose infusions for about $3 \mathrm{hr}$. The kidneys were then removed and frozen in liquid nitrogen. The second group, which was used to study the effi:cts of DDAVP on medullary c-AMP content, was handled according to a protocol identical to that mentioned previously.

\section{ANALYSES}

Inulin was analyzed in urine and in serum by the anthrone method (7). Plasma was deproteinized with $0.33 \mathrm{~N}$ perchloric acid. Urea in plasma and urine was analyzed using the Berthelot reaction (Asid Diagnostica, Lohhof-Munich, West Germany). Osmolarity in plasma and urine was determined by freezing point depression. Using the test kit for the radio isotope dilution test with A-3:5-MP-binding protein of Boehringer (Mannheim, West Germany), c-AMP was determined. This method was first described by Gilman (9). Determinations of c-AMP in: 1) urine: depending upon its osmolarity, urine was diluted by double

Table 1. Development of renal response in urinary concentration to DDAVP during neonatal period ${ }^{1}$

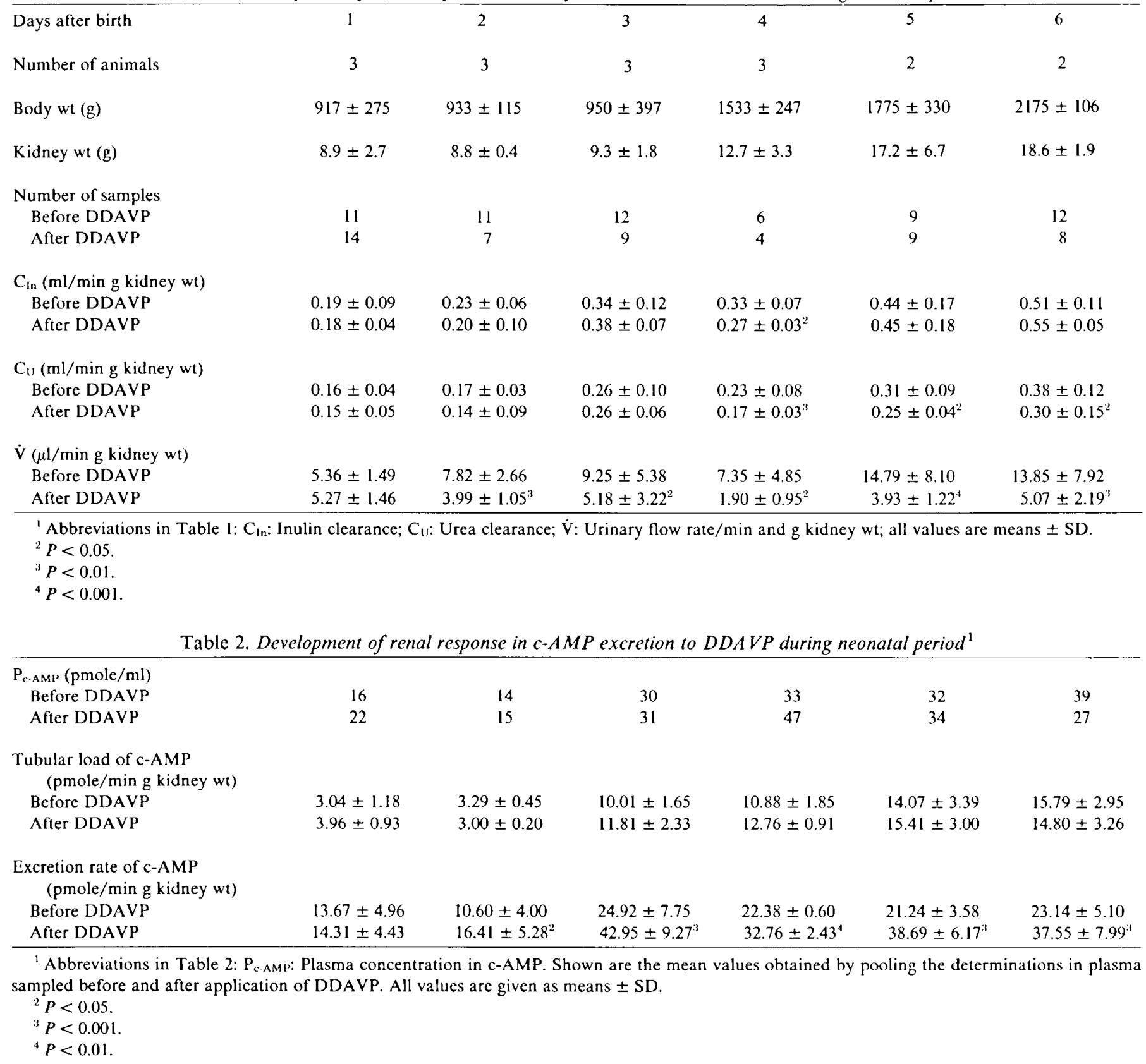


distilled water and added without any further preparation into the test assay. 2) in plasma: plasma was prepared as described by Hamet et al. (13). The recovery rates were about $80 \%$. 3) in medullary tissue: the frozen kidneys were placed on an aluminium plate and kept at a temperature of $-10^{\circ} \mathrm{C}$. The medulla was separated from the cortex and dissected into slices of 100-200 mg. Each slice was weighed, added to $2 \mathrm{ml}$ of ice cold $1 \mathrm{~N}$ perchloric acid and homogenized in a Potter $\mathrm{S}$ homogenizer (Braun Melsungen, West Germany). For recovery, $0.01 \mu \mathrm{Ci}{ }^{3} \mathrm{H}$-c-AMP (Boehringer, Mannheim) was added. The homogenate was then centrifuged and the supernatant purified by aluminum oxide and Dowex- 50 columns as described by Jacobs et al. (14). The recovery rates were about $70 \%$.

\section{CALCULATIONS}

Linear regression analysis was performed using the method of least squares. The results are expressed as means \pm SD. Student's $t$ test was used to test for significant differences between mean values or paired values.

\section{RESULTS}

Table 1 shows that GFR as measured by inulin clearance increased progressively during the observed period. Its magnitude was not affected significantly by the application of DDAVP. A regression line was calculated between the number of days after birth and the values of GFR, obtained before and after infusion of DDAVP, which is given to be $\mathrm{Y}=0.07 \mathrm{X}+0.1(P<0.001, r$ $=0.72$ ).

In Table 1 it can be seen that the infusion of glucose solution during control brought about an increase in urinary flow rate. This effect increased significantly from day 2 onwards. Parallel to the development of the diuretic response during control, the application of DDAVP was followed progressively with age by a significant decrease of urinary flow rate (see Table 1), a significant increase in $U / P_{\text {osmol }}$ (see Fig. 1) and $U / P_{I n}$ (see Fig. 2).

As Table 1 shows, during the first 3 days after birth, urea clearance developed parallel to inulin clearance. In addition, $\mathrm{U} / \mathrm{P}_{\text {urea }} / \mathrm{U} / \mathrm{P}_{\mathrm{In}}$ was insensitive to DDAVP and much higher than in mature organ (see Fig. 3 and Table 1).

From day 4 onwards, urea clearance, as measured during control phase, developed less than inulin clearance, indicating that the reabsorbed fraction of filtered urea began to increase. In addition, absolute and fractional urea clearance decreased significantly after application of DDAVP. As Figure 3 shows, this effect increased progressively with age during the observed period.

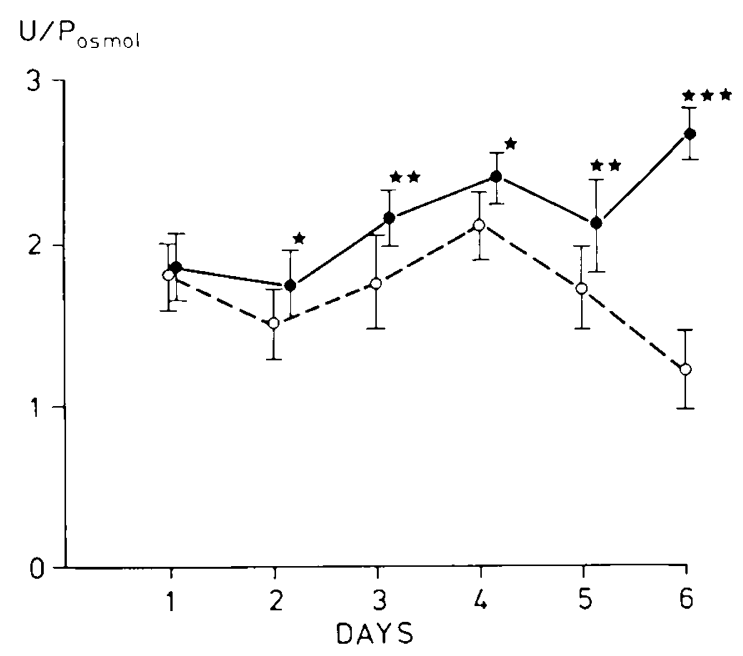

Fig. I. Effects of DDAVP on relative urinary osmolarity $\left(U / \mathrm{P}_{\text {osmol }}\right.$ during the first 6 days of life. Dashed line: control values. Solid line: steady state values after DDAVP. All values are given as means $\pm S D$. The asterisks represent the level of significance of differences between the control and the test values. ${ }^{*}: P<0.05 ;{ }^{* *}: P<0.01 ;{ }^{* *}: P<0.001$.
Within the period studied, DDAVP had no effects upon plasma c-AMP concentration (see Table 2) or GFR (see Table 1). Thus, tubular load of c-AMP was also unaffected by the application of DDAVP. However, from day 2 to day 6 , renal c-AMP excretion rate in response to DDAVP increased progressively (see Table 2). Hence, DDAVP increased the nephrogenic fraction of renal cAMP excretion rate as calculated to be the difference between renal excretion rate and tubular load in proportion with age (see Fig. 4). In a second series of measurements on 16 animals, the development of medullary c-AMP formation in response to DDAVP was studied by measurement of medullary c-AMP content. The data are given in Fig 5. In control animals which had received isotonic glucose infusions, but no DDAVP, medullary cAMP content ranged between $636 \pm 258$ pmole/g wet wt on day

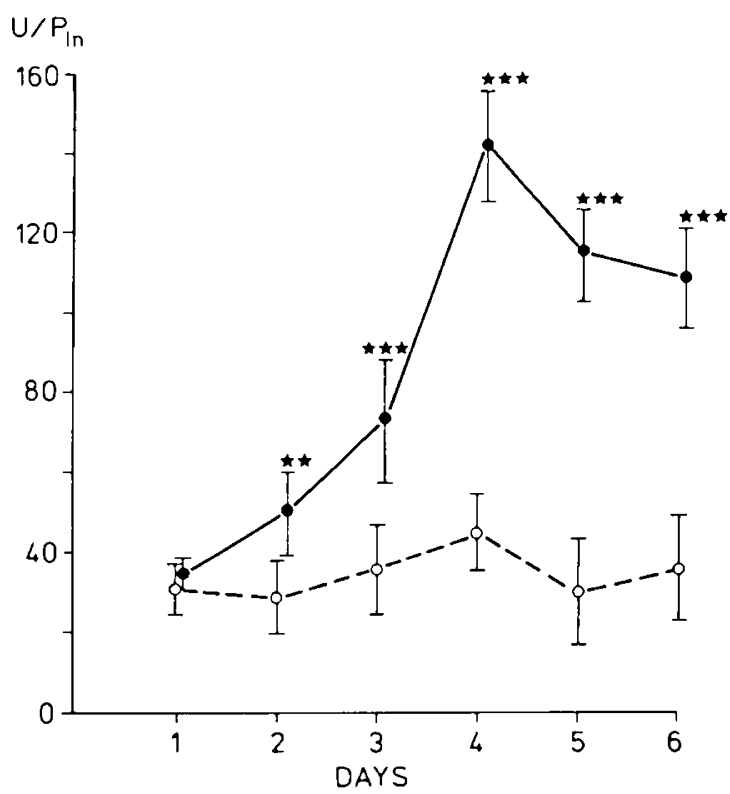

Fig. 2. Effects of DDAVP on fractional water excretion $\left(U / P_{I n}\right)$ during the first 6 days of extrauterine life. Dashed line: control values. Solid line: steady state values after DDAVP. All values are given as means \pm SD. The asterisks represent the level of significance of the differences between the test and the control values. ${ }^{*}: P<0.05{ }^{* *}: P<0.01 ;{ }^{* *}: P<0.001$.

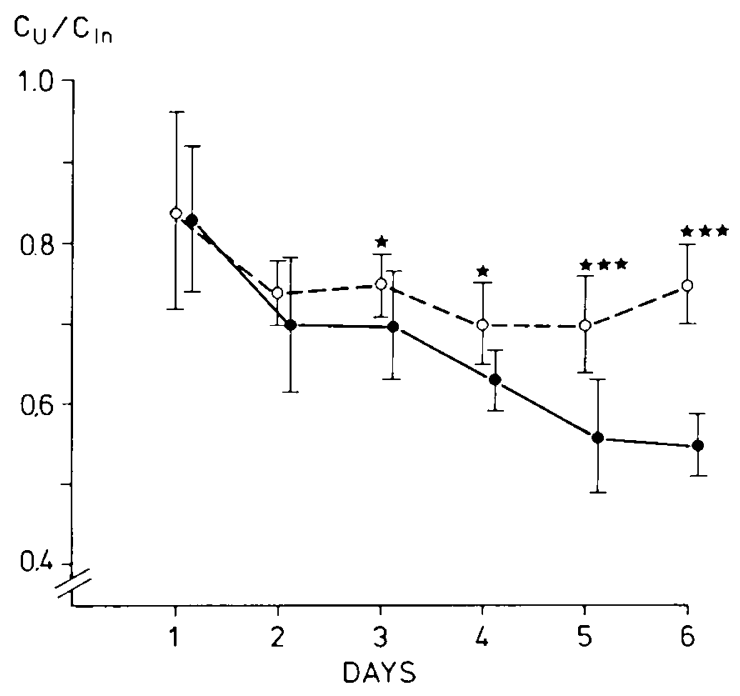

Fig. 3. Effects of DDAVP on fractional urea clearance $\left(\mathrm{C}_{11} / \mathrm{C}_{\mathrm{In}}\right)$ during the first 6 days of life. Dashed line: control values. Solid line; steady state values after the application of DDAVP. All values are given as means \pm SD. The asterisks represent the level of significance of the differences between the control and the test values after DDAVP. ${ }^{*}: P<0.05{ }^{* *}: P$ $<0.01 ;{ }^{* * *}: P<0.001$. 
1 and $622 \pm 75$ pmole/g wet wt on day 6 . These values didn't differ significantly from each other at the different days after birth. However, in animals, which had received DDAVP, medullary c-AMP content increased significantly from day 2 onward and in proportion with age (see Fig. 5).

\section{DISCUSSION}

Our experiments were performed on piglets in vivo because there exist corresponding studies in vitro on preparations from the same animal $(4,15,20)$. With respect to their small blood volume, ADH cannot be determined directly. Therefore, we studied the inhibitory effect of a given dose of DDAVP on water diuresis (3), modified by the effects of anaesthesia $(10,11)$, and the diminished dilution capacity of the thick ascending limbs (27).

Within the observation period of our experiments, the response of the newborn pig kidney to DDAVP developed in three phases. Phase 1: On the day of birth, DDAVP had no effect on $U / P_{\ln }$ and $\mathrm{U} / \mathrm{P}_{\text {urea }} / \mathrm{U} / \mathrm{P}_{\mathrm{In}}$ or on, $\mathrm{U} / \mathrm{P}_{\text {osmmll }}$. It is possible that the hormone cannot elicit an increase in the water and urea permeabilities of

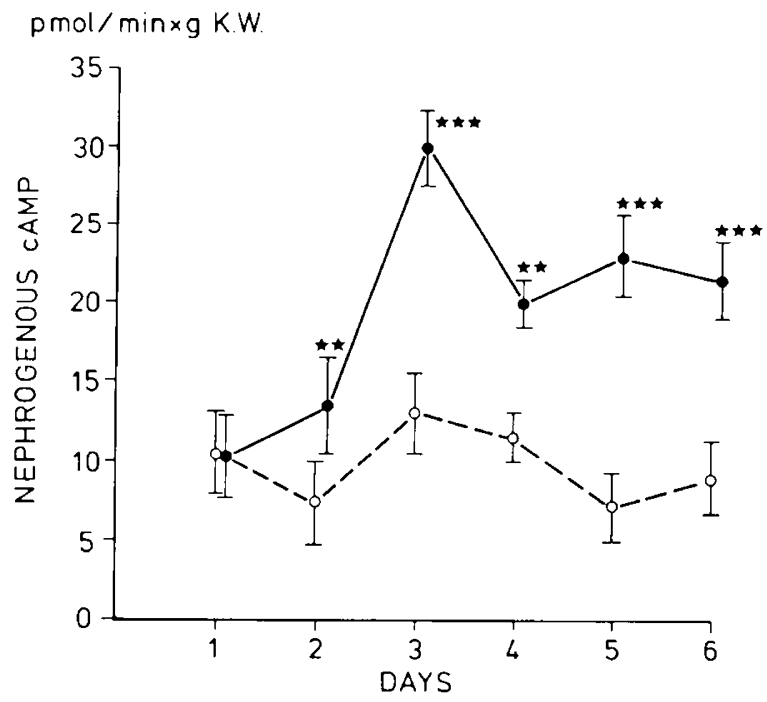

Fig. 4. Effects of DDAVP on renal excretion of nephrogenic c-AMP during the first 6 days of life. Dashed line: control values. Solid lines: steady state values after DDAVP. All values are given as means \pm SD. The asterisks represent the level of significance between the control values and the test values after DDAVP. ${ }^{*}: P<0.05{ }^{* *}: P<0.01 ;{ }^{* *}: P<$ 0.001 .

the collecting ducts, and, in addition, that the countercurrent system cannot provide an osmotic gradient along the medulla which is sufficient to remove significant amounts of water. Phase 2: On day 2 and 3, the application of DDAVP led to an increase of only fractional water reabsorption; fractional urea reabsorption remained low and practically independent of the presence of ADH. From this fact and the observations that urea does not accumulate in the medulla of infant rats after urea loading (24), and the fact that ADH has no effect upon the corticomedullary solute gradient in newborn piglets (23), one may speculate that, in our studies, DDAVP elicited an increase of water, but not urea permeability. This might be due to a small medulla:cortex ratio (24). Because the cortical collecting ducts are effectively urea impermeable $(1,12)$, while the inner medullary collecting duct urea permeability (25) is ADH sensitive, development of the inner medulla would lead to an increase of urea reabsorption. Phase 3: The responses on day 5 and 6 , were characterized by increasing effects of DDAVP on fractional water and urea reabsorption and on urinary osmolarity in a manner similar to that observed in adult mammals. This indicates that urea can diffuse out of the medullary collecting ducts and that it can accumulate in the medulla. Hence, it seems that all the functions of the countercur- rent system necessary for the production of concentrated urine are developed, even if GFR is still low, and the growth of the kidneys and the development of maximal concentrating ability is not yet complete.

In our study, DDAVP had no effects on the formation rate of nephrogenic c-AMP and on medullary tissue c-AMP content on the first day of life. This phenomenon may be explained by two observations made in vitro: 1) On membrane preparations of the medulla of young rats and rabbits $(19,21)$, the activity of renal adenylate-cyclase was found to be reduced in the neonatal state in comparison to the adult state. 2) The activity of the phosphodiesterase in the renal medulla of the newborn rat seems to be increased in comparison to the mature state $(8,17)$. Because c-AMP is the mediator of the effects of ADH on the collecting ducts, it is possible that in our studies, beside the reduced formation rate, a higher breakdown of c-AMP caused by increased phosphodiesterase activity may have led to a reduced response in permeability of the medullary collecting ducts after DDAVP. This view is supported by our observation by a parallelism between the development of the effects of DDAVP on fractional water reab-

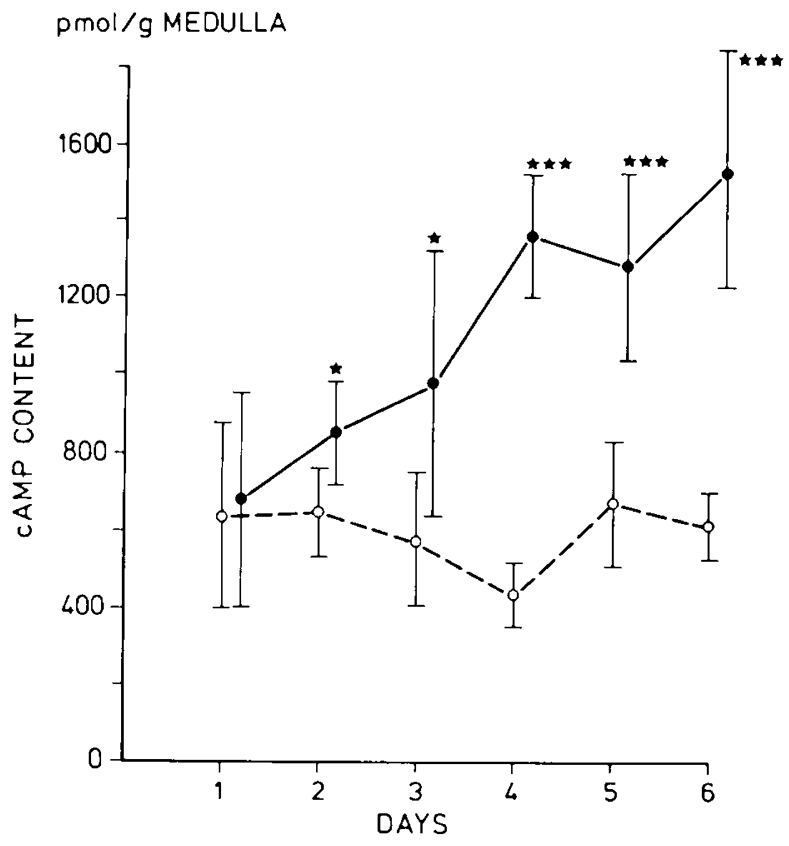

Fig. 5. Effect of DDAVP on medullary c-AMP content during the first 6 days of life. Dashed line: controls. Solid line: values obtained after application of DDAVP. The asterisks represent the level of significance between the values obtained without and after DDAVP. ${ }^{*}: P<0.05 ;{ }^{* *}$ $P<0.01 ;{ }^{* * *}: P<0.001$.

sorption, and the increase of both, the nephrogenic c-AMP formation rate and medullary c-AMP contenc in response to DDAVP. In addition, when c-AMP is substituted by the infusion of dibutyryl-c-AMP and phosphodiesterase is inhibited, a significant increase of renal concentrating capacity can be observed even on the day of birth, a time when, in this study, no effect of DDAVP was observed (16). Hence, it seems reasonable to assume that in addition to the findings reported above, the diminished concentrating capacity of the newborn kidney may be related, in part, to a "functional" lack of intracellular c-AMP due to altered activities of the enzymes of the c-AMP pathway.

\section{REFERENCES AND NOTES}

1. Al-Zahid, G., Schafer, J. A., Troutman, S. L., and Andreoli Th. E.: Effect of antidiuretic hormone on water and solute permeation, and the activation energies for these processes, in mammalian cortical collecting tubules. J. Membrane Biol., 31: 103 (1977).

2. Boss, J. M. N., Dlouha, H., Kraus, M., and Krecek, J.: The structure of the 
kidney in relation to age and diet in white rats during the weaning period. $J$. Physiol., 168: 196 (1963).

3. Dicker, S. E.: Mechanisms of Urine Concentration and Dilution in Mammals. p. 143 (Arnold, London, 1970).

4. Dousa, T., Hechter, O., Schwartz, 1. L., and Walter, R.: Neurohypophyseal hormone-responsive adenylate cyclase from mammalian kidney. Proc. Natl. Acad. Sci. USA. 68: 1693 (1971).

5. Edelmann, C. M. Jr., and Barnett. H. L.: Role of the kidney in metabolism in young infants: physiological and clinical considerations. J. Pediatr., 56: 154 (1960).

6. Edelmann. C. M. Jr., Barnett, H. L., and Troupkou, V.: Renal concentrating mechanisms in newborn infants. Effects of dietary protein and water content, role of urea, and responsiveness to antidiuretic hormone. J. Clin. Invest., 39: $1062(1960)$

7. Führ, J., Kaczmarczyk, J., and Küttgen, C. D.: Eine einfache Methode zur Inulinhestimmung für Nieren-Clearance-Untersuchungen bei Stoffwechselgesunden und Diabetikern. Klin. Wschr., 33: 729 (1955).

8. Gengler, W. R., Forte, L.: Neonatal development of rat kidney adenylcyclase and phosphodiesterase. Biochem. Biophys. Acta, 279: 367 (1972).

9. Gilman, A. G.: A protein binding assay for adenosine-3',5'-cyclic monophosphate. Proc. Natl. Acad. Sci. USA, 67: 305 (1970).

10. Ginsburg, M.: Production, release, transportation and elimination of the neurohypophyseal hormones. In: B. Berde: Handbook of Experimental Pharmacology. Vol. 23 (Springer, Berlin, Heidelberg, New York, 1968).

11. Goodman, S. L., and Gilman, A.: In: H. L. Price and R. D. Dripps: The Pharmacological Basis of Therapeutics. Chap. 8, 3rd Edition. p. 115 (Macmillan, New York 1966).

12. Grantham, J. J., and Burg. M.: Effect of vasopressin and cyclic AMP on permeability of isolated collecting tubules. Am. J. Physiol., 211: 255 (1966).

13. Hamet, P., Kuchel, O., Fraysse, J., and Genest, J.: Plasma adenosine-3',5'-cyclic monophosphate in human hypertension. Can. Med. Assoc. J., 11: 323 (1974).

14. Jacobs, K. H., Böhme, E., and Schultz, G.: Determination of cyclic GMP in biological material. In: J. E. Dumont, B. L. Brown and M. J. Marshall: Eukaryotic cell function and growth. Regulation by intracellular cyclic nucleotides. p. 295 (Plenum Press, New York and London, 1976).

15. Jard, S., Roy, C., Barth. T., Rajerison, R., and Bockaert, J.: Antidiuretic hormonesensitive kidney adenylate cyclase. In: G. I. Drummond, P. Greengard, and G A. Robinson: Advances in Cyclic Nucleotide Research. Vol. S, p. 31 (Raven Press, New York, 1975).

16. Joppich, R., Kiemann, U., Ruhland, G., and Häberle, D.: Einflu $\beta$ des antidiure- tischen Hormons auf das renale Adenyzyklase-System and die Konzentrierungsfähigkeit des neugeborenen Schweines. XII sympos. d. Gesellschaft $\mathrm{f}$. Nephrol., R 31, p. 18, (Urban und Schwarzenberg. München, 1977).

17. Kleinman, L. I., Wald, A., and Czazkes, J. W.: Maturation of renal enzymes in newborn rats. Pediatr. Res (abstract) 11: 553 (1977).

18. Martinek. J., Janovský, M., Stanincová, V., and Slechtová, R.: The effect of vasopressin on the water diuresis and excretion of $\mathrm{Na}, \mathrm{Cl}, \mathrm{K}$ and urea in infants. Nephron, $1: 322$ (1964).

19. Rajerison, R., Butlen, D., and Jard, S.: Ontogenetic development of antidiuretic hormone receptors in rat kidney: comparison of hormonal bindings and adenylcyclase activity. Mol. Cell. Endocrine., 4: 271 (1976).

20. Roy, C., Barth, I., and Jard, S.: Vasopressin-sensitive kidney adenylate cyclasestructural requirements for attachment to receptor and enzyme activationstudies with vasopressin analogues. J. Biol. Chem., 250: 3149 (1975).

21. Schlöndorff, D., Fine, L., Trizna. W.. and Weber. H.: Hyporesponsiveness of adenylate cyclase from neonatal kidney membranes and isolated collecting tubules to vasopressin. Kidney Int., (Abstract) 10: 598 (1976).

22. Speller, A. M., and Moffat, D. B.: Tubulo-vascular relationships in the developing kidney. J. Anat., 123: 487 (1977).

23. Stainer, M. W.: Development of intra-renal solute gradients in foetal and postnatal life. Pflügers Arch., 336: 263 (1972).

24. Trimble, M.: Renal response to solute loading in infant $i$ ats: relation to anatomical development. Am. J. Physiol., 219: 1089 (1970).

25. Ullrich, L. J., Rumrich, G., and Schmidt-Nielsen, B.: Urea transport in the collecting duct of rats on normal and low protein diet. Pflügers Arch., 295: 147 (1967).

26. Vávra, I., Machová, A., Holecek, V., Cort, J. H., Zaoral, M., and Sorm, F. Effects of a synthetic analogue of vasopressin in animals and in patients with diabetes insipidus. Lancet, I: 948 (1968).

27. Zink, H., and Horster, M.: Maturation of diluting capacity in loop of Henle of rat superficial nephrons. Am. J. Physiol., 233: F 519 (1977).

28. The authors thank Dr. Leon Moore for his editorial assistance, and Prof. $\mathrm{K}$. Thurau for his interest in this work.

29. This research was supported by Deutsche Forschungsgemeinschaft Bonn-Bad Godesberg, Federal Republic of Germany.

30. Requests for reprints should be addressed to: Dr. R. Joppich, UniversitätsKinderklinik, Lindwurmstrasse 4,D-8000 Munich 2, Federal Republic of Germany.

31. Received for publication May 16, 1978.

32. Accepted for publication August 8,1978 